This is the peer reviewed version of the following article:

Iridium-catalyzed Formyl-selective Deuteration of Aldehydes, W.J. Kerr, M. Reid and T. Tuttle, Angew. Chem. Int. Ed., 2017, doi: 10.1002/anie.201702997

which has been published in final form at:

http://onlinelibrary.wiley.com/doi/10.1002/anie.201702997/abstract

This article may be used for non-commercial purposes in accordance With Wiley-VCH Terms and Conditions for self-archiving 


\title{
Iridium-catalyzed Formyl-selective Deuteration of Aldehydes
}

\author{
William J. Kerr, ${ }^{*}$ Marc Reid, and Tell Tuttle*
}

\begin{abstract}
We report the first direct catalytic method for formylselective deuterium labeling of aromatic aldehydes under mild conditions, using an iridium-based catalyst designed to favor formylover aromatic $\mathrm{C}-\mathrm{H}$ activation. A good range of aromatic aldehydes is selectively labeled, and a one-pot labeling/olefination protocol is also described. Computational studies support kinetic product control over competing aromatic labeling and decarbonylation pathways.
\end{abstract}

Catalyst design for site-selective $\mathrm{C}-\mathrm{H}$ activation is a prominent and important area of on-going research in organic synthesis. ${ }^{[1]}$ To this end, deuterium labeling provides an insightful means of probing catalyst activity and $\mathrm{C}-\mathrm{H}$ bond selectivity, either for isotope incorporation itself, or to underpin further synthetic transformations. ${ }^{[2]}$ In this regard, based on the versatility of isotopically-labeled aldehydes as building blocks for use in mechanistic and pharmaceutical science, a small number of studies have reported hydrogen isotope exchange (HIE) on the formyl moiety, albeit accompanied by aryl labelling (Scheme 1, top). ${ }^{[3]}$ Despite the distinct nature of the aromatic and aldehyde positions, little effort appears to have been made to develop a formyl-selective HIE direct from the unlabeled aldehyde. ${ }^{[4]}$ Herein, we report our preliminary investigations to establish such a formyl-selective labeling of aryl aldehydes.

Our previous studies on the iridium-catalyzed deuteriumlabeling of aromatic carbonyl derivatives ${ }^{[2]]}$ have showed that a

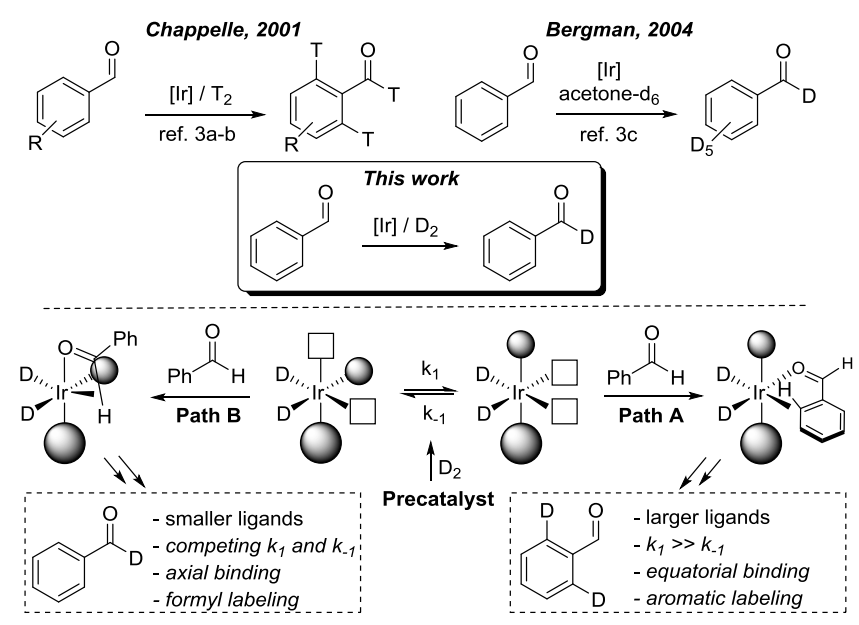

Scheme 1. Ir-catalyzed labeling of aldehydes and mechanistic hypothesis.

trans-oriented bulky ligand pair results in equatorial directing group binding and consequent aryl $\mathrm{C}-\mathrm{H}$ activation (Scheme 1 Path A). We hypothesized, therefore, that a smaller, cis-enabled ligand pair would facilitate axial aldehyde binding and subsequent formyl C-H activation (Path B). ${ }^{[5]}$ Importantly, this proposed ligand-controlled pathway would also avoid the need for an additional directing group on the aryl ring of the substrate. ${ }^{[6]}$

To initiate our studies, we screened a small number of iridium complexes with large/large and large/small ligand pairs. Using 2-naphthaldehyde, 1, as a model substrate, we first examined the large/large ligand partnership, using pre-catalysts of the type $\left[(C O D) \operatorname{Ir}\left(L^{1}\right)\left(L^{2}\right)\right] P F_{6}$, commonly used in orthodirected aryl labeling (Scheme 2). ${ }^{[2,7]}$ In accordance with earlier stoichiometric tritiation work, ${ }^{[3 a, b]}$ the use of Crabtree's catalyst, $2,{ }^{[8]}$ led to appreciable levels of labeling across both the aromatic and formyl positions. Remarkably, employing our more encumbered phosphine/ $\mathrm{N}$-heterocyclic carbene $(\mathrm{NHC})$ catalyst $3,{ }^{[2,9]}$ led to a dramatic switch in labeling selectivity in favor of near-exclusive aryl labeling. Thus, these observations are in line with our original hypothesis regarding increasing the bulk of the ligand pair (Scheme 1, Path A). ${ }^{[10]}$

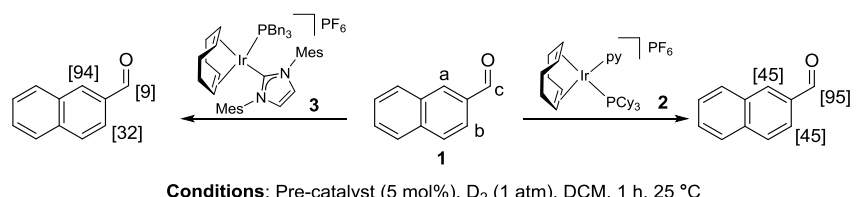

Scheme 2. Hypothesis testing for aryl-selective labeling of aldehydes.

Following our proposed catalyst design for a formyl-selective aldehyde labeling, we discovered that the large/small ligand combination in $\mathrm{NHC/chloro} \mathrm{catalyst} \mathbf{4 a},{ }^{[11]}$ bearing an overall smaller ancillary ligand sphere than $\mathbf{2}$ or $\mathbf{3}$, delivered appreciably encouragingly levels of formyl labeling selectivity (Scheme 3 ). Although other $\mathrm{NHC/Cl}$ catalysts displayed similar activity, ${ }^{[10]}$ only catalyst $\mathbf{4 b}$ maximized formyl labeling whilst completely suppressing formation of decarbonylated by-product $\mathbf{5}$. It should

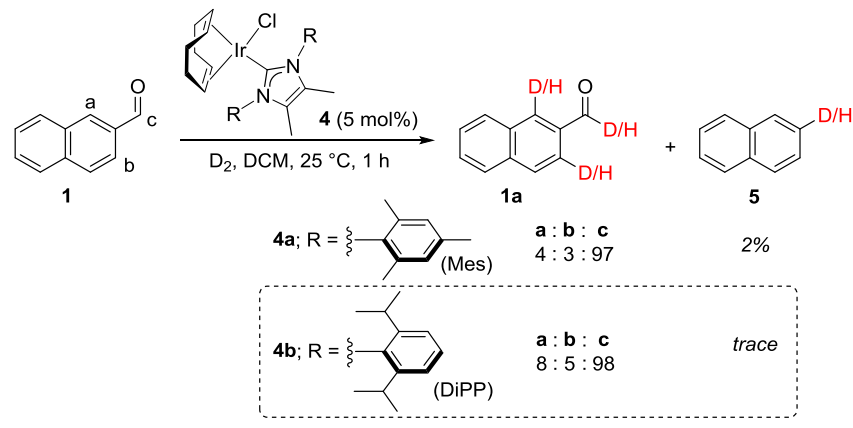

Scheme 3. Catalyst discovery for formyl-selective aldehyde labeling.
Department of Pure and Applied Chemistry, WestCHEM

University of Strathclyde, 295 Cathedral Street

Glasgow, Scotland, G1 1XL (U.K).

E-mail:w.kerr@strath.ac.uk; t.tuttle@strath.ac.uk

Supporting information for this article is given via a link at the end of the document. 


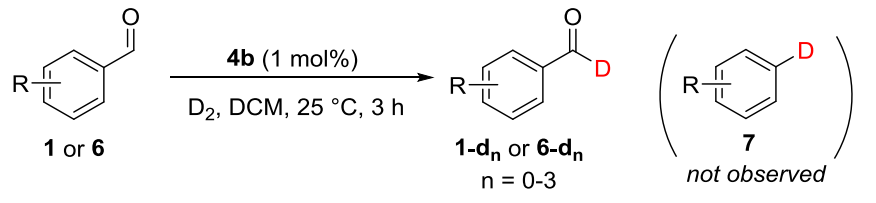

\begin{tabular}{|c|c|c|c|c|c|}
\hline Entry & Aldehyde & $\mathrm{R}$ & $\begin{array}{c}\text { Formyl } \\
\% \mathrm{D}\end{array}$ & $\begin{array}{l}\text { Aryl } \\
\% \mathrm{D}\end{array}$ & Yield, \% \\
\hline 1 & $6 a$ & $\mathrm{H}$ & 93 & - & 90 \\
\hline 2 & $6 b$ & $4-\mathrm{OBn}$ & 97 & 19 & 88 \\
\hline 3 & $6 c$ & $4-\mathrm{OH}$ & 93 & 8 & 95 \\
\hline 4 & $6 \mathrm{~d}$ & 4-Ph & 94 & - & 97 \\
\hline 5 & $6 e$ & $4-\mathrm{CF}_{3}$ & 95 & - & 95 \\
\hline 6 & $6 f$ & $4-\mathrm{Cl}$ & 97 & - & 96 \\
\hline 7 & $6 \mathrm{~g}$ & $4-\mathrm{Br}$ & 97 & - & 73 \\
\hline 8 & $6 \mathrm{~h}$ & $4-\mathrm{F}$ & 97 & 8 & 63 \\
\hline 9 & $6 i$ & 4-Me & 98 & 12 & 80 \\
\hline 10 & $6 \mathrm{j}$ & $4-\mathrm{NO}_{2}$ & 98 & - & 80 \\
\hline 11 & $6 \mathrm{k}$ & $3-\mathrm{Br}$ & 96 & - & 70 \\
\hline 12 & 61 & $3-\mathrm{NO}_{2}$ & 99 & - & 95 \\
\hline $13^{[a]}$ & $6 \mathrm{~m}$ & $3-\mathrm{CF}_{3}$ & 75 & - & 80 \\
\hline $14^{[\mathrm{a}]}$ & $6 n$ & 3,5-di-Me & 78 & - & 63 \\
\hline 15 & 1 & 2-naphthaldehyde & 96 & - & 96 \\
\hline 16 & 60 & 1-naphthaldehyde & 24 & - & 85 \\
\hline
\end{tabular}

[a] Reaction performed using $2.0 \mathrm{~mol} \% \mathbf{4 b}$

also be noted that, in agreement with our initial hypothesis, the use of complexes with even more sterically demanding $\mathrm{NHC}$ ligands decreased the formyl selectivity and, indeed, overall catalyst reactivity. ${ }^{[10]}$

Further investigation of the reaction conditions allowed optimal catalyst $\mathbf{4 b}$ to be employed at loadings of $1-2 \mathrm{~mol} \%$ by extending the reaction time from $1 \mathrm{~h}$ to $3 \mathrm{~h} \cdot{ }^{[10]}$ Under these optimized conditions, a range of aromatic aldehydes were selectively deuterated. As depicted in Table 1, unsubstituted and para-substituted benzaldehydes $(\mathbf{6} \mathbf{a}$, and $\mathbf{6} \mathbf{b}-\mathbf{6} \mathbf{j})$ were labeled with good to excellent regioselectivity and isolated yields, with a low level of aryl labeling detectable in only a few examples. A series of meta-substituted substrates $(\mathbf{6 k - 6 n})$ were also welltolerated, while more encumbered aldehydes, such as 1naphthaldehyde 60 , remain challenging. Under the employed conditions, the decarbonylation product 7 was not observed with any of the substrates.

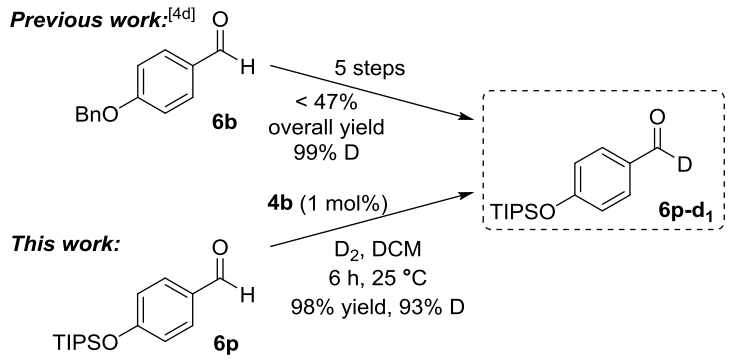

Scheme 4. Improved synthetic route to labeled aldehyde $6 p-d_{1}$.

In a further demonstration of the utility of this catalytic formyl labeling method, we have shown that silyl-protected phenol $6 p$, employed in the synthesis of enantiopure $d_{1}$-benzyl alcohols, ${ }^{[4 d]}$ could be successfully labeled in a single, high-yielding step and with a high level of deuterium incorporation (Scheme 4). This method is superior to the existing route ${ }^{[4 d]}$ to the same product, which employed stoichiometric quantities of reagents and required five steps starting from alternative aldehyde, $\mathbf{6 b}$.

In a further extension of this work, we demonstrated that the potentially air-sensitive $d_{1}$-aldehydes need not be isolated, but can instead be further elaborated in one pot, for example, via Horner-Wadsworth-Emmons olefination ${ }^{[12]}$ (Scheme 5). Importantly, the resulting $\beta$-deuterated, $\alpha, \beta$-unsaturated esters 8a-c have not been accessed by direct labeling of the corresponding cinnamate esters. ${ }^{[13]}$ Most notably, this procedure also allowed the method to be extended to the labeling of aliphatic aldehydes, such as in derivative $\mathbf{8 c}$, with only minor levels of deuterium incorporation at the enolisable site.
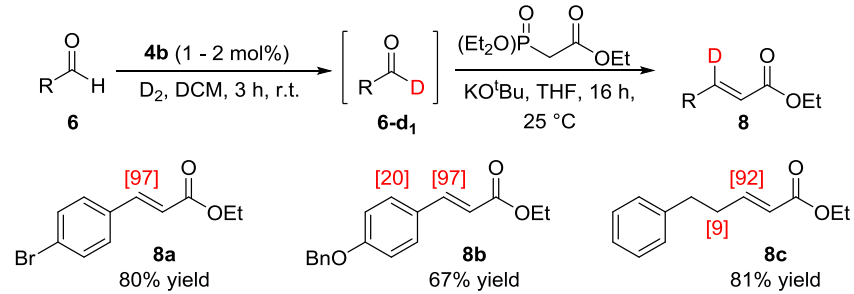

Scheme 5. One pot formyl labeling and olefination of aldehydes.

With an applicable and robust formyl labeling method in hand, our attention turned to preliminary mechanistic investigations into the hypotheses underpinning catalyst design. Firstly, we established that the presence of the chloride ligand in the optimal catalyst $\mathbf{4 b}$ was crucial, as replacement with the more labile acetonitrile ligand in complex 9 resulted in low levels of D-incorporation and equal amounts of aryl vs formyl C-H activation (Scheme 6); additionally, introduction of a series of silver salts in combination with complex $\mathbf{4 b}$ led to complete arrest of the catalytic formyl labeling. ${ }^{[10]}$ Secondly, 4(benzyloxy)benzyl alcohol was subjected to the optimized conditions (but with $\mathrm{H}_{2}$ instead of $\mathrm{D}_{2}$ ), in order to detect any aldehyde formation. ${ }^{[10]}$ In this case, $<2 \%$ conversion to the corresponding aldehyde was observed, suggesting that a 


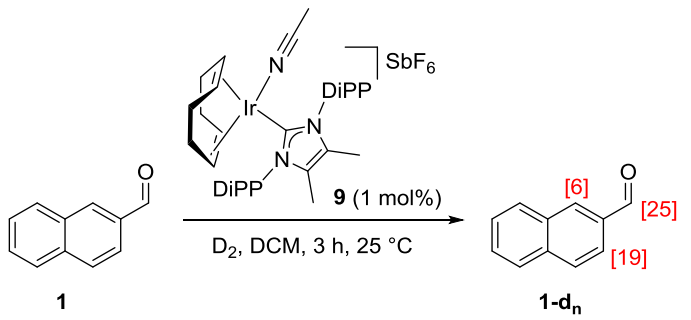

Scheme 6. Investigating the effect of the chloride ligand.

hydrogen borrowing mechanism ${ }^{[14]}$ plays only a minor role.

Further to these initial experimental studies, density functional theory (DFT) has been utilized to model proposed labeling mechanisms consistent with both the initial hypothesis and all available experimental evidence. ${ }^{[15]}$ To begin, the free energy differences in the DCM-solvated cis- and trans-isomers of the deuterium-activated catalysts derived from pre-catalysts $\mathbf{2}$, 3, and 4b were assessed (Scheme 7). In the progression towards more formyl-selective labeling catalysts $(\mathbf{3} \rightarrow \mathbf{2} \rightarrow \mathbf{4 b}$ ), the trans/cis energy gap diminishes. Moreover, the energetic order of the cis- and trans-isomers was shown to be reversed on moving to the optimized catalyst, $\mathbf{4 b}$, with its $\Delta \mathrm{G}_{\text {cis/trans }}$ being the smallest of the three catalysts studied.

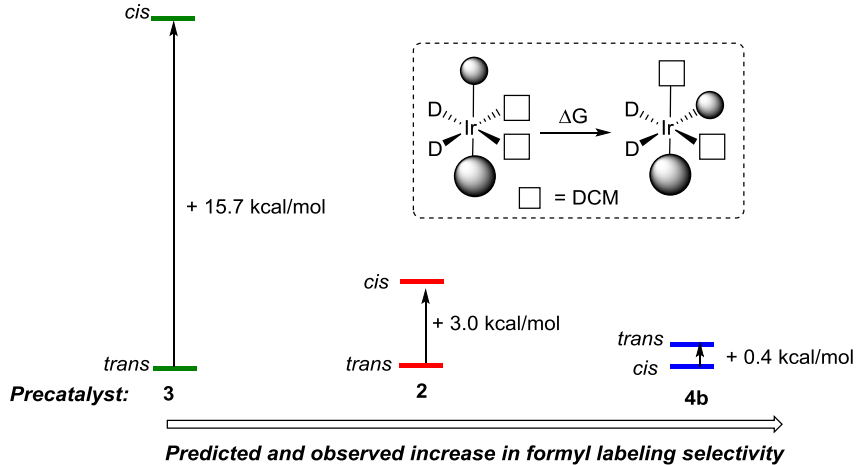

Scheme 7. Computational support for cis/trans ligand model.

Following this initial modelling study, the mechanistic details of the competing labeling processes were investigated for substrate $\mathbf{6 a}$ with catalyst $\mathbf{4 b}$. Overall, three competing pathways are proposed, which account for the three observed products: aryl labeling, formyl labeling, and decarbonylation (Scheme 8). The aryl labeling pathway is calculated to proceed via an all$\operatorname{Ir}(\mathrm{III})$ cycle with trans ancillary ligands (10-13), as elucidated in our earlier reports. ${ }^{[2,11]}$ In contrast, and in comparison with the labeling of sulfonamides using iridium $\mathrm{NHC} /$ chloro complexes of type $4,{ }^{[11]}$ a distinct mechanism for aldehyde $\mathrm{C}-\mathrm{H}$ activation with these catalysts is revealed by the computed formyl labeling pathway. More specifically, after catalyst activation, the cis ancillary ligand geometry in $\mathbf{1 4}$ allows axial coordination of the aldehyde and subsequent formyl $\mathrm{C}-\mathrm{H}$ activation to give $\operatorname{Ir}(\mathrm{V})$ complex 15. From this intermediate, our DFT studies strongly support reductive elimination of two of the three hydrides to give dihydrogen complex 16, which can return to $\operatorname{Ir}(\mathrm{V})$ via oxidative re-addition of the bound hydrogen to give 17 , with a further deuteride now cis to the acyl ligand. ${ }^{[15]}$ Reductive elimination from intermediate $\mathbf{1 7}$ then gives the labeled, bound aldehyde in complex 18, in a microscopic reverse of the initial activation step $(14 \rightarrow 15)$. Finally, the productive, formyl labeling cycle may partition at $\operatorname{Ir}(\mathrm{III})$ intermediate 16, with decarbonylation of the acyl ligand via migratory insertion $(\mathbf{1 6} \rightarrow \mathbf{1 9})$. Reductive elimination of the decarbonylation by-product from 19 leads to carbonyl complex 20.

Following extensive binding conformer comparisons, ${ }^{[15]}$ the lowest potential energy surfaces (PESs) for aryl, formyl, and decarbonylative labeling are summarized in Scheme 9. Consistent with experiment, formyl labeling represents the lowest energy pathway. The formyl $\mathrm{C}-\mathrm{H}$ activation $(\mathbf{1 4} \rightarrow \mathbf{1 5})$ is predicted to be enthalpically flat on the PES, with the $\operatorname{Ir}(\mathrm{V}) \rightarrow \operatorname{Ir}(\mathrm{III})$ reductive elimination $(\mathbf{1 5} \rightarrow \mathbf{1 6})$ being turnoverlimiting. From transition state calculations, the formyl activation

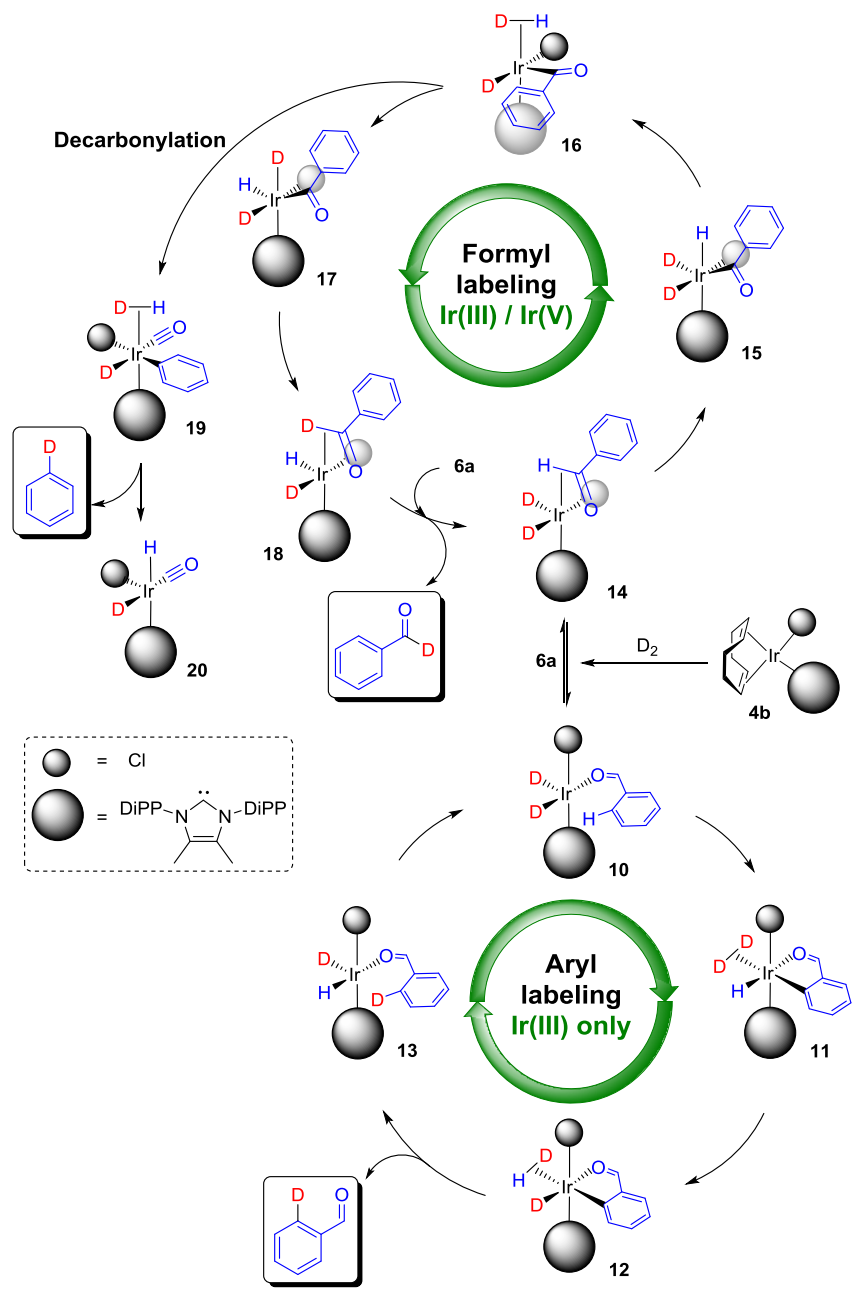

Scheme 8. DFT mechanisms for aryl, formyl, and decarbonylative labeling. 


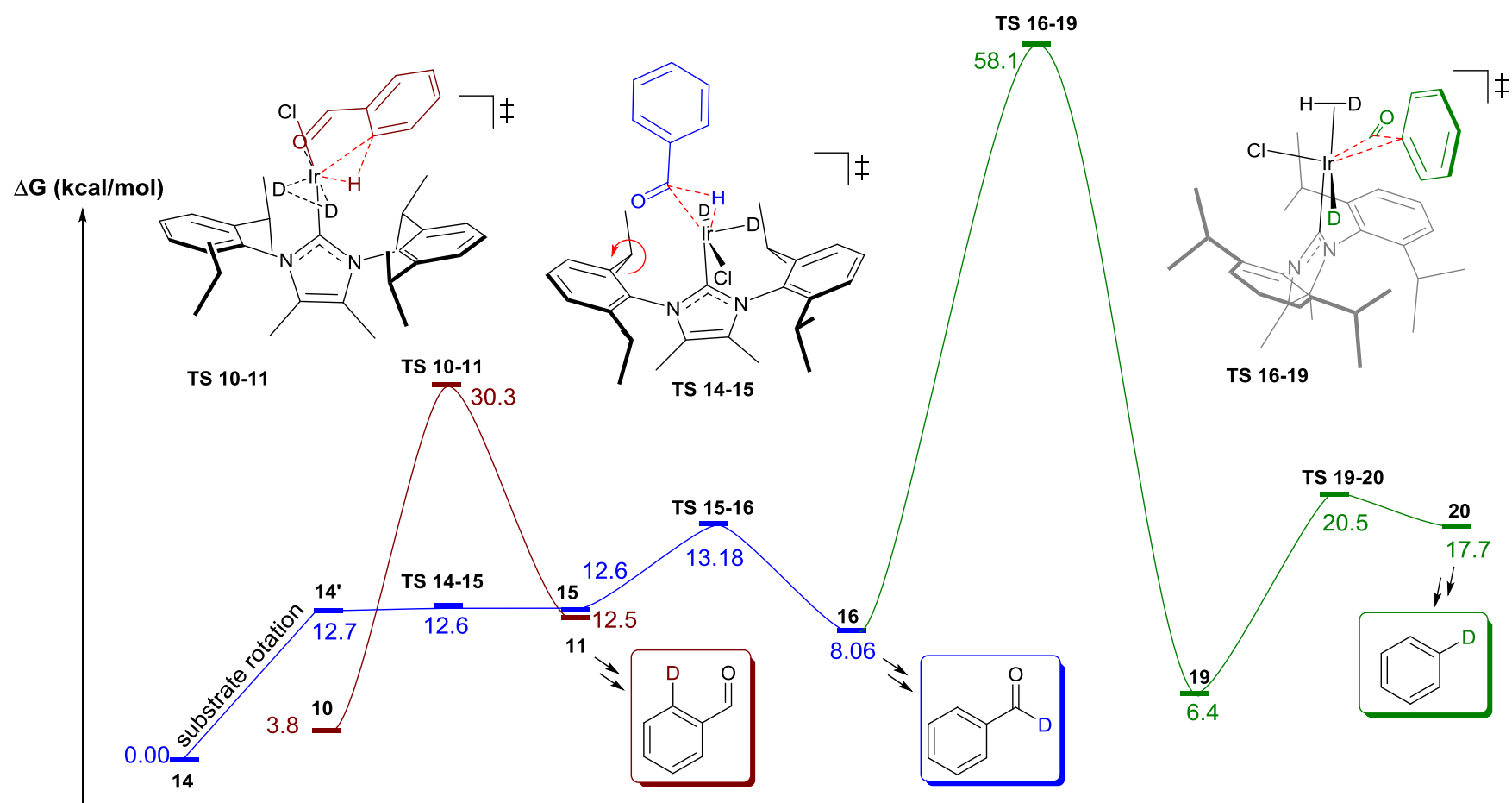

Scheme 9. Calculated PESs for formyl vs. aryl vs. decarbonylative labeling. ${ }^{[15]}$

step is seen to be coupled with a rotation of one iso-propyl group on the ligand to accommodate the substrate (TS 14-15 in Scheme 9$)^{[15]}$ Conversely, the barrier to the classical ortholabeling process (TS 10-11) is unproductively high relative to formyl labeling. ${ }^{[16]}$ Finally, the partition towards decarbonylation (TS 16-19) represents the most energetically unfavorable of all these processes at the catalytically-relevant temperature $(298.15 \mathrm{~K})$; this is in qualitative agreement with only trace observation of such by-products.

In summary, we have developed a mild and highly selective catalytic process for the formyl $\mathrm{C}-\mathrm{H}$ labeling of a range of functionalized aryl aldehydes. This direct method is an improvement on existing stepwise routes towards preparatively important and pharmaceutically-valuable $\mathrm{d}_{1}$-aldehydes, and can also be employed in a one-pot process leading to derivatization of the labeled formyl moiety. DFT analysis supports competition between an $\operatorname{Ir}(\mathrm{III})$ catalytic cycle for aryl labelling, and previously unreported $\operatorname{Ir}(\mathrm{III}) / \mathrm{Ir}(\mathrm{V})$ cycles for formyl labeling and partitioning decarbonylation. Based on these initial investigations, further studies on the site-selective $\mathrm{C}-\mathrm{H}$ activation of aldehydes are currently underway in our laboratory and will be reported in due course.

\section{Acknowledgements}

W.J.K. and M.R. would like to thank the Carnegie Trust for funding, and the EPSRC UK National Mass Spectrometry Facility at Swansea University for analyses.
Keywords: C-H activation $\bullet$ aldehyde $\bullet$ deuterium $\bullet$ iridium $\bullet$ DFT

[1] For selected reviews, see: a) N. Kuhl, M. N. Hopkinson, J. WencelDelord, F. Glorius, Angew. Chem. Int. Ed. 2012, 51, 10236-10254; Angew. Chem. 2012, 124, 10382-10401; b) J. Wencel-Delord, T. Dröge, F. Liu, F. Glorius, Chem. Soc. Rev. 2011, 40, 4740-4761; c) D. Balcells, E. Clot, O. Eisenstein, Chem. Rev. 2010, 110, 749-823; d) V. Ritleng, C. Sirlin, M. Pfeffer, Chem. Rev. 2002, 102, 1731-1770; (e) B. G. Hashiguchi, S. M. Bischof, M. M. Konnick, R. A. Periana, Acc. Chem. Res. 2012, 45, 885-898.

[2] For selected examples of metal-catalyzed labeling, see: a) S. Ma, G. Villa, P. S. Thuy-Boun, A. Homs, J.-Q. Yu, Angew. Chem. Int. Ed. 2014, 53, 734-737; Angew. Chem. 2014, 126, 753-756; b) M. H. Emmert, J. B. Gary, J. M. Villalobos, M. S. Sanford, Angew. Chem. Int. Ed. 2010, 49, 5884-5886; Angew. Chem. 2010, 122, 6020-6022; c) A. Di Giuseppe, R. Castarlenas, J. J. Pérez-Torrente, F. J. Lahoz, V. Polo, L. A. Oro, Angew. Chem. Int. Ed. 2011, 50, 3938-3942; Angew. Chem. 2011, 123, 4024-4028; d) J. Campos, A. C. Esqueda, J. López-Serrano, L. Sánchez, F. P. Cossio, A. de Cozar, E. Álvarez, C. Maya, E. Carmona, J. Am. Chem. Soc. 2010, 132, 16765-16767; e) L. Neubert, D. Michalik, S. Bähn, S. Imm, H. Neumann, J. Atzrodt, V. Derdau, W. Holla, M. Beller, J. Am. Chem. Soc. 2012, 134, 12239-12244; f) A. Prades, M. Poyatos, E. Peris, Adv. Synth. Catal. 2010, 352, 1155-1162; g) M. H. G. Prechtl, M. Hölscher, Y. Ben-David, N. Theyssen, R. Loschen, D. Milstein, W. Leitner, Angew. Chem. Int. Ed. 2007, 46, 2269-2272; Angew. Chem. 2007, 119, 2319-2322; h) M. Parmentier, T. Hartung, A. Pfaltz, D. Muri, Chem. Eur. J. 2014, 20, 11496-11504; i) J. A. Brown, A. R. Cochrane, S. Irvine, W. J. Kerr, B. Mondal, J. A. Parkinson, L. C. Paterson, M. Reid, T. Tuttle, S. Andersson, G. N. Nilsson, Adv. Synth. Catal. 2014, 356, 3551-3562.

[3] a) M. R. Chappelle, A. D. Morgan, N. C. O. Tomkinson, T. M. Willson, in Synth. Appl. Isotop. Lab. Comp. Proceedings of the 7th International Symposium (Eds.: U. Pleiss, R. Voges), Wiley, New York, 2001, pp. 
80-83; b) M. R. Chappelle, C. R. Hawes, J. Labelled Compd. Radiopharm. 2010, 53, 745-751; c) M. B. Skaddan, C. M. Yung, R. G. Bergman, Org. Lett. 2004, 6, 11-13.

[4] For examples of generating labeled aldehydes from alternative precursors, see: a) J. T. Spletstoser, J. M. White, G. I. Georg Tetrahedron Lett. 2004, 45, 2787-2789; b) S. B. Boga, A. B. Alhassan, D. Hesk, Tetrahedron Lett. 2014, 55, 4442-4444; c) S. Korsager, R. H. Taaning, A. T. Lindhardt, T. Skrydstrup, J. Org. Chem. 2013, 78, 6112 6120; d) D. W. Barnett, M. S. Refaei, R. W. Curley Jr., J. Labelled Compd. Radiopharm. 2013, 56, 6-11.

[5] Previous studies in the Rh- and Ir-catalyzed decarbonylation of aldehydes have enforced this substrate binding mode via bidentate ligand design. See, for example: a) E. P. K. Olsen, T. Singh, P. Harris, P. G. Andersson, R. Madsen, J. Am. Chem. Soc. 2015, 137, 834-842 b) E. P. K. Olsen, R. Madsen, Chem. Eur. J. 2012, 18, 16023-16029; c) P. Fristrup, M. Kreis, A. Palmelund, P.-O. Norrby, R. Madsen, J. Am. Chem. Soc. 2008, 130, 5206-5215.

[6] J. F. Hooper, R. D. Young, A. S. Weller, M. C. Willis, Chem. Eur. J. 2013, 19, 3125-3130.

[7] For selected reviews in ortho-directed deuterium and -tritium labeling, see: a) G. N. Nilsson, W. J. Kerr, J. Labelled Compd. Radiopharm. 2010, 53, 662-667; b) R. Salter, J. Labelled Compd. Radiopharm. 2010 53, 645-657; c) J. Atzrodt, V. Derdau, T. Fey, J. Zimmermann, Angew. Chem. Int. Ed. 2007, 46, 7744-7765; Angew. Chem. 2007, 119, 7890 7911; d) J. R. Heys, J. Labelled Compd. Radiopharm. 2007, 50, 770 778.

[8] R. H. Crabtree, H. Felkin, G. E. Morris, J. Organomet. Chem. 1977, 141 205-215.

[9] a) A. R. Cochrane, S. Irvine, W. J. Kerr, M. Reid, S. Andersson, G. Nilsson, J. Labelled Compd. Radiopharm. 2013, 56, 451-454; b) A. R. Cochrane, C. Idziak, W. J. Kerr, B. Mondal, L. C. Paterson, T. Tuttle, S. Andersson, G. N. Nilsson, Org. Biomol. Chem. 2014, 12, 3598-3603; c) A. R. Kennedy, W. J. Kerr, R. Moir, M. Reid, Org. Biomol. Chem. 2014 12, 7927-7931; d) J. Atzrodt, V. Derdau, W. J. Kerr, M. Reid, P. Rojahn, R. Weck, Tetrahedron 2015, 71, 1924-1929; e) J. Devlin, W. J. Kerr, D. M. Lindsay, T. J. D. McCabe, M. Reid, T. Tuttle, Molecules 2015, 20 , 11676-11698; f) P. W. C. Cross, J. M. Herbert, W. J. Kerr, A. H. McNeill, L. C. Paterson, Synlett 2016, 27, 111-115.

[10] For further details, see the electronic supporting information (ESI).

[11] W. J. Kerr, M. Reid, T. Tuttle, ACS Catal. 2015, 5, 402-410.

[12] B. E. Maryanoff, A. B. Reitz, Chem. Rev. 1989, 89, 863-927.

[13] For selected examples of labeling $\alpha, \beta$-unsaturated substrates directly, see: a) W. J. Kerr, R. J. Mudd, L. C. Paterson, J. A. Brown, Chem. Eur J. 2014, 20, 14604-14607; b) W. J. S. Lockley, Tetrahedron Lett. 1982 , 23, 3819-3822.

[14] P. J. Black, G. Cami-Kobeci, M. G. Edwards, P. A. Slatford, M. K. Whittlesey, J. M. J. Williams, Org. Biomol. Chem. 2006, 4, 116-125.

[15] Details of all calculation methods, along with additional calculations not presented in the manuscript, can be found in the ESI.

[16] The barrier to aryl $\mathrm{C}-\mathrm{H}$ insertion is $7.4 \mathrm{kcal} / \mathrm{mol}$ lower in energy when using catalyst 3 , for which formyl labeling is also disfavoured, consistent with the observed ortho-selectivity with 3 (Scheme 2); see the ESI. 


\section{Entry for the Table of Contents}

\section{COMMUNICATION}

Al(D)hydes. An iridium catalyst system has been designed to effect formyl over aryl $\mathrm{C}-\mathrm{H}$ activation of aromatic aldehydes. Computational studies support kinetic product control over competing aromatic labeling and decarbonylation pathways.
Prof. Dr W. J. Kerr, ${ }^{*} \operatorname{Dr}$ M. Reid, and Dr T. Tuttle*

\section{Page No. - Page No.}

Iridium-catalyzed Formyl-selective Deuteration of Aldehydes 